INTERNATIONAL DESIGN CONFERENCE - DESIGN 2018

https://doi.org/10.21278/idc.2018.0315

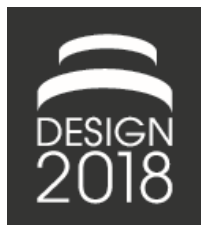

\title{
SIMULATION-SUPPORTED PARTICIPATIVE PROCESSES IMPROVEMENT IN ENGINEERING DESIGN
}

\author{
L. Becerril and U. Lindemann
}

\begin{abstract}
In today's dynamic environment, companies need to adapt their design processes faster than ever. Lack of employee involvement has been highlighted as a main issue during the adoption of new processes in R\&D. Existing participatory methods, e.g. in ergonomics, contribute to ease organizational changes. However, their applicability on complex processes is limited. By combining methods from ergonomics and user experience with dynamic process models, we propose an approach that enables process stakeholders (e.g. engineers) to give feedback and to test the planned process in a range of scenarios.
\end{abstract}

Keywords: participatory design, design process, change management

\section{Introduction}

In today's dynamic global economy, organizations that resist change often lose ground to their competitors, thus adopting new processes or systems becomes necessary for survival (Rebentisch, 2017). However, adopting new processes involves a lot of effort, time, and costs (including trainings, software, pilot projects) and the results are not always satisfactory. The change implementation failure rates in organizations has been found to be up to $70 \%$ (Todnem By, 2005). Moreover, lack of employee involvement is highlighted as an issue in change projects in R\&D departments (c.f. Becerril et al., 2018).

Existing participatory methods, for example in ergonomics, have been found to ease the implementation process (Daniellou, 2007). The outcome of these methods, as feedback, can be integrated in the design of the future work system (Andersen and Broberg, 2017).

Nevertheless, the applicability of existing participatory methods for product development processes is limited. Processes in engineering design have a long duration, have very complex interrelations (Negele et al., 1997), are ill-defined (Maier and Störrle, 2011), and unique - since they aim to create something new (Browning et al., 2006). A process evaluation approach that includes the people in the engineering design process and their experiences and context is missing. This paper proposes the SimulationSupported Participative Process Improvement (S2P2I) framework that improves acceptance and implementation of Engineering Design Processes through enabling the "process users" to play a part in the design of complex and dynamic development processes. This is achieved by combining participatory methods from ergonomics and risk management, with dynamic process models.

The following section provides a brief understanding of products development processes, and their challenges. Then selected existing user integration methods in work contexts are described. The third section depicts the methodology of this research, while the fourth section described the resulting approach for integration of process participants in the context of engineering design. 


\section{Background}

This section provides a brief overview of the definitions and current understanding in the fields of product development processes, user integration methods in process design, and dynamic simulation of processes and projects. Additionally, it emphasises the untapped potential between participatory design methods and dynamic simulations.

\subsection{Product development and engineering design processes}

"A process consists of a number of tasks that need to be carried out and a set of conditions that determine the order of the tasks. A process can also be called a procedure" (van der Aalst and van Hee, 2004). In contrast to business and manufacturing processes, which are easier to reengineer or improve towards some dimension (Browning et al., 2006, p. 11), the domains in engineering design are highly connected. Due to the high number of interdependences, Engineering Design (ED) processes can be better described as networks or webs instead of as chains (Negele et al., 1997; Browning et al., 2006, p. 11). However, not only the processes and structures are interlinked, but documents, IT-systems, and the protagonists of the process who communicate with each other (Kreimeyer, 2009). Hereafter, improving ED processes requires the involvement and mutual calibration of all perspectives and domains (Herfeld, 2007; Kreimeyer, 2009; Hellenbrand, 2013).

Moreover, deliverables in ED processes are virtual and not always well defined. These range from data, information, product specifications, concepts, ideas, designs, to trials (and errors) (Vajna, 2005; Helten, 2015). Thus, the outputs of many PD activities cannot be verified until much later (Browning et al., 2006, p. 11). Especially in the early phases, ED processes have to deal with high uncertainty, ambiguity and risk (Browning et al., 2006; Lévárdy and Browning, 2009; Maier and Störrle, 2011; Kasperek, 2016).

"Few products are developed by a single individual" (Ulrich and Eppinger, 2003, p. 3). Virtually all instances of ED processes require the collaborative effort of many people. Most design instances involve a great number of people, distributed over space, time, and organisations (Maier and Störrle, 2011).

In the context of this paper, the "process system" comprises activities and decisions, deliverables, roles, IT Systems and databases, rules and practices, and performance indicators, as well as their interrelations among each other.

\subsection{Current user integration methods in processes design or improvement}

This section presents and overview on existing methods on involving users or stakeholders in the design of processes. The methods presented below are rooted in Usability and User Experience, Risk Management, Ergonomics, and (Management) Education, although some derivations of the methods are applied in other areas. Nevertheless, this is not a comprehensive list but comprises those directly or indirectly relevant to the approach presented in this paper. The methods described here were selected according to following criteria:

- They evaluate a period of time rather than an isolated point.

- They are forming methods, which in contrast to tests, provide insights on how to improve the evaluated system.

- They (or their extensions) have been applied to a work environment

\section{The Socio-Technical Walkthrough (Herrmann, 2009)}

In the Socio-Technical Walkthrough (STWT) a model of the socio-technical system to develop is evaluated and incrementally modified within a series of workshops (Herrmann, 2009, p. 344). The STWT is partially based on the "Cognitive Walkthrough" (Polson et al., 1992).

In the Socio-Technical Walkthrough the goal is to create or evaluate a concept or an outline of a sociotechnical system, which is represented by a set of models. These models can developed from scratch or derived from existing work processes (Herrmann, 2009, p. 344). During the STWT the workshop facilitator reveals parts of the model and ask questions to the participants - for example "What is the next sensible activity?" or "Which information support is needed for this activity?" (Herrmann, 2009, pp. 345-346). Moreover, participants deliver hints, proposals and comments regarding the socio- 
technical system (Herrmann, 2009, pp. 345-346). The participants' contributions are then documented in the process models, integrating the different perspectives into a larger picture (Herrmann, 2009, pp. 345-346).

\section{Customer Journey Map and User Experience Journey}

The customer journey map is a visual, process-oriented representation of the interaction between customers and an organization (Nenonen et al., 2008). It depicts and structures people's experiences and takes in account the customers' mental models, the interactions and touch points between organizations and their customers (Nenonen et al., 2008).

A similar approach, applied to research projects, is the Project Experience Map by (Thurgood et al., 2016). Moreover, an extension of the CJM tailored for products is the User Experience (UX) Journey by (Kremer et al. 2017). User Experience (UX) summarizes "how a user expects, perceives and assesses an encounter with a product." (Roto et al., 2011).

The UX Journey which represents the experience and concerns of users graphically. Within the UX Journey data for evaluating every user-product interaction is acquired through user interviews with help of predefined questions. The users assess UX elements in defined scale. Then, UX indices are calculated for every touchpoint based on the users' assessments and other input data. (Kremer et al., 2017).

\section{Risk FMEA (Carbone and Tippett, 2015)}

Failure Mode and Effects Analysis (FMEA) is a widespread instrument for identifying and analysing risks. Some adaptations of this method include Scenario-based FMEA, Life-cost FMEA, Project FMEA, and Assembly process FMEA (Chao and Ishii, 2007, p. 492). The Project Risk FMEA (RFMEA) is an extension of the FMEA that aims to quantify and analyse project risks (Carbone and Tippett, 2015, p. 28). For this purpose, risk events are identified in a team brainstorming in the form of "If $x$ happens, then $\mathrm{y}$ will occur," where $\mathrm{x}$ is the risk event and $\mathrm{y}$ is the impact of the event happening. (Carbone and Tippett, 2015, p. 31). Moreover, Carbone and Tippett (2015) propose modifications to the FMEA, such as specific time, cost and technical impact value guidelines or adding additional project details to the template. In this manner, the RFMEA technique helps focus early in the project on critical risks (Carbone and Tippett, 2015, p. 31).

\section{Participatory simulation (PS)}

Participatory simulation (PS) is a method from the field ergonomics that involves workers in "simulating and designing their own future work system" (Andersen and Broberg, 2017). The goal of this methodology is to identify ergonomic challenges and possible improvements early on - before the work system is implemented (Andersen and Broberg, 2017). The activities of Participatory Simulation include participants sharing work experiences, experimenting with scenarios, and reflecting on the consequences of the new work system (Andersen and Broberg, 2017). Applications of PS include for example, a case of design of a new outpatient clinic at a hospital where a group of workers (physicians, nurses and secretaries) from the existing clinic used table top simulations with help of cardboard boxes and LEGO figures to optimize the new clinic layout (Broberg, 2015).

\section{Methodology}

The results presented in this paper addresses the research question "how can process stakeholders be efficiently involved in the design of a complex R\&D process?" In previous work (Becerril et al., 2018), "lack of employee involvement" was identified as a main issue during the adoption of new processes in $\mathrm{R} \& \mathrm{D}$ departments in a literature survey and practitioners interviews.

Moreover the main contributions of the S2P2I Framework is applying known methods to new environment, as well as develop additional support templates and methods for their application in practice.

The applicability of the S2P2I Framework was evaluated in two student workshops, using mock-ups of simulations of a different process each time. The participants could evaluate the processes using the materials and methodology provided, however could not evaluate the direct benefit since they were not involved in said processes. To evaluate its effectiveness, two case studies in industry are planned for early 2018 . 


\section{The simulation-supported participative process improvement approach}

The simulation-supported participative process improvement (S2P2I) in engineering design aims

- to gain feedback from process users and experts (engineers, designers, product managers, etc.),

- to generate knowledge with regard of context dependent and subjective factors that affect process performance,

- to test the planned process in a range of scenarios,

- and to facilitate these users to participate in the improvement of the processes that shape their daily work.

The S2P2I approach is based on the participative simulation methodology and the user journey mapping, and is adapted to evaluate complex processes without overwhelming the participants or oversimplifying the process-to-improve. Here, process users are assigned tasks and goals that they try to achieve within given scenarios. Scenarios are ought to be "prototypes" of processes and are supported with dynamic simulations. The simulations allow to depict complex and emergent behaviors of product development processes with relative low effort.

Figure 1 depicts the S2P2I approach, which is divided in two main phases and four steps. The first phase is the preparation phase where the simulation base-model is developed and the relevant scenarios, key stakeholders and their tasks are identified. The second phase, the evaluation phase, comprises the evaluation workshop and the definition of improvement points for the target process. Both phases are described in detail in the corresponding section below. Moreover, the improvement process is iterative; where the evaluation phase can be revisited sometime after the process improvement measures have been implemented. Additionally, key steps are supported by methods and tools, which will be addressed in detail in the corresponding sections below.

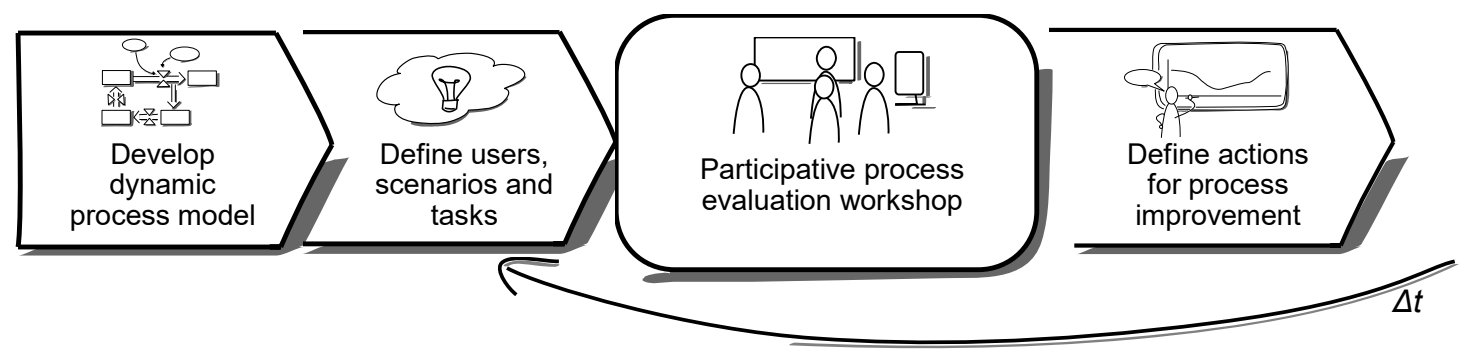

Figure 1. S2P2I approach

According to (Daniellou, 2007) the basic components of a participative simulation are:

- the social construction of the overall participatory process;

- the choice of the participants;

- the choice of the simulation media and the type of simulation;

- the choice of simulation scenarios.

In the case of product development processes, the choice of participants and the choice of simulation scenarios are highly dependent on the company and its situation, thus they should be defined case by case. Choosing the participants and the scenarios is part of the second step in the depicted approach.

Moreover, the simulation media is a central component of this approach. Simulation media is, for example mockups, prototypes or game boards that represent the initial design of the future work system (Daniellou, 2007). Design objects are manipulated during the workshops and should be in tangible format (Broberg et al., 2011, p. 470). As emphasized before, engineering design processes are complex, unique, and have a long duration. Thus, we use dynamic simulation models, such as Agent Based Models, as design objects throughout the workshops.

\subsection{Preparation phase}

The goal of this phase is to obtain the necessary material for planning and executing the participative evaluation workshop, as well as to further clarify the goals of the process analysis. As mentioned in the 
introduction, this approach requires a (draft) process as starting point, which can be modelled in a DSM, workflow language, or as boxes and arrows. Thus, the first step is to transform these static models into a dynamic model (e.g. into System Dynamics). Then, the workshop facilitator (e.g. the process or project manager) defines who will participate in the simulation (or which roles) and which scenarios will be executed. Furthermore, each of the proposed steps is realized through a series of sub-steps and with help of supporting methods, which are described below.

\subsubsection{Develop dynamic base-model}

The goal of this step is to transform a static process model into a dynamic base-model, which can be simulated. However to ensure applicability, the dynamic model needs to be affordable and realistic at the same time. This apparent conflict is solved by using a further development of Structure-based System Dynamics by (Kasperek, 2016), which is partly automatized within the "model transformation tool". For developing the dynamic base model, the five steps illustrated in Figure 2 are suggested.

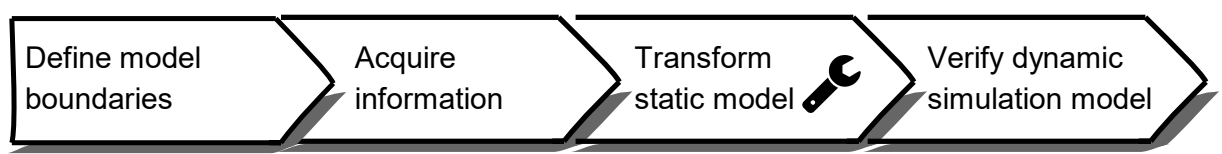

Figure 2. Steps for developing the dynamic base-model

The first step, the model definition, comprises the definition of system's boundaries (i.e. which part of the process and which interfaces). Then, existing static process models are enhanced with the required information for developing a dynamic process model.

In the third step, the modeler structures the process model and the acquired information as necessary and imports it into the transformation tool. The transformation tool delivers a system dynamics simulation model. However, a verification step is recommended. Here, a sensitivity analysis or an extreme conditions test (c.f Sterman, 2000, p. 858) can be used to verify that the transformed model presents a realistic behavior. For reasons of space, this paper does not addresses the detailed transformation framework and tool.

\subsubsection{Defining user scenarios and tasks}

Because the participants and scenarios shape the focus of the evaluation, this step also comprises the further direction of improvement. Therefore, as a first step the goals of the workshop should be further clarified. Afterwards, different scenarios are identified.

Then a stakeholder map (Figure 3) illustrates the people or roles involved in the process, as well as their relationships.

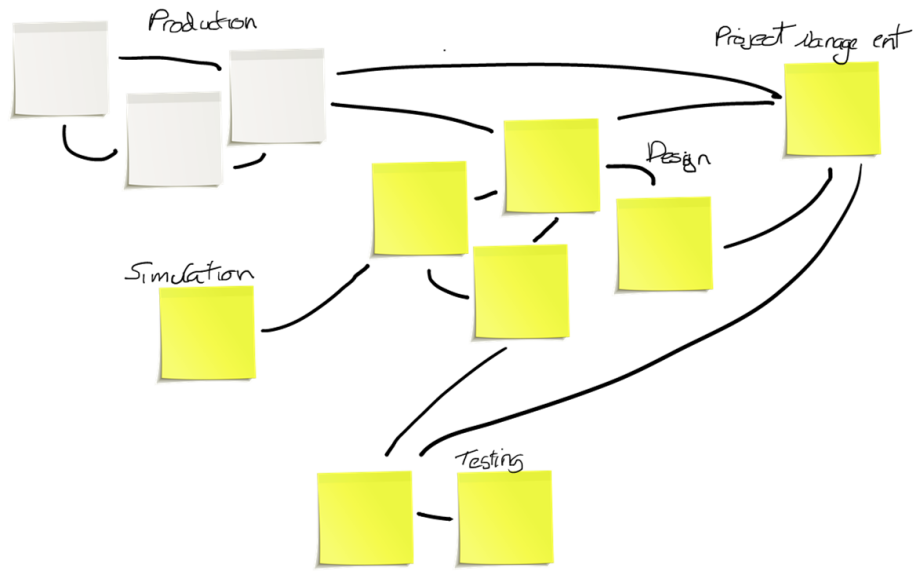

Figure 3. Stakeholder map

The third step comprises the mapping of the scenarios developed in step two and the stakeholders identified. For this purpose a DMM can be used, as illustrated in Figure 4. Then, the workshop lead 
selects the scenario/stakeholder combinations that suit the defined goals. This can be supported with an $\mathrm{ABC}$ Analysis and/or a Consistency Matrix. Lastly, the scenarios are implemented into the dynamic simulation model.
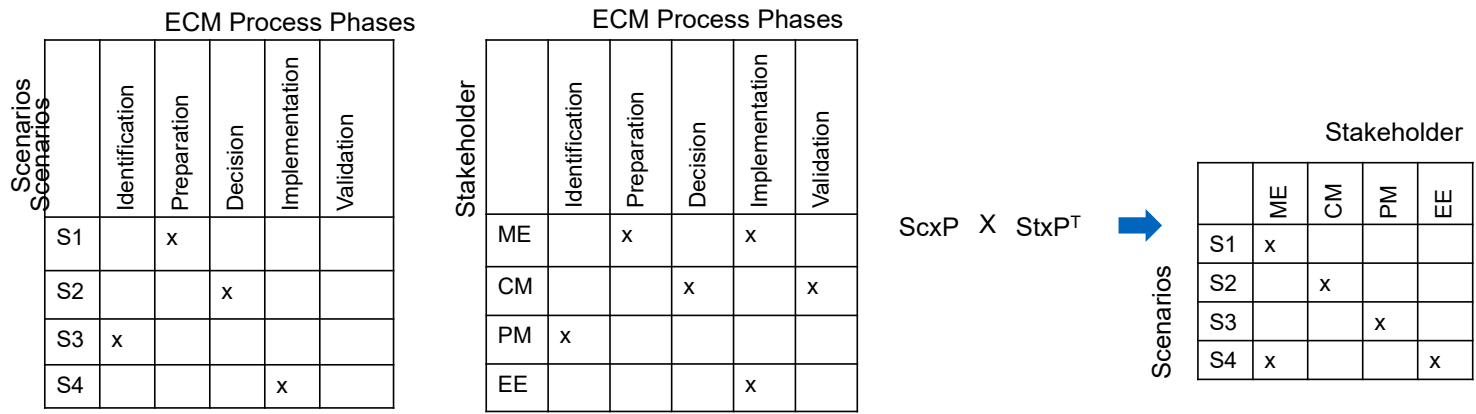

Figure 4. Mapping scenarios and stakeholders

\subsection{Evaluation phase}

The evaluation phase comprises the participative simulation workshop itself, the recording of insights during the workshop and the interpretation of results afterwards. The process improvement measures are developed in this phase as well, however these are highly specific to each company, process and situation.

\subsubsection{Participative simulation workshop}

The participatory simulation workshop is the main part of the S2P2I approach. Here, the participants (i.e. the selected process users) execute the defined scenarios supported by the simulation model. (Andersen and Broberg, 2017) suggest two activities in participatory simulations: sharing work experiences, which includes "asking other participants" and "sharing own work", and experimenting, which comprises "what-if discussions" and "scenario acting". In this approach we recommend all four types of sub-activities, however the tools presented below focus on "experimenting". Moreover, we developed or adapted three templates for recording the results of the scenario acting and the what if discussions, as illustrated in Figure 5. The Journey Map and the transparency questionnaire are addressed below. Additionally, we suggest using the risk FMEA (Carbone and Tippett, 2015, p. 31) during what-if discussion when discussing undesired scenarios or events.

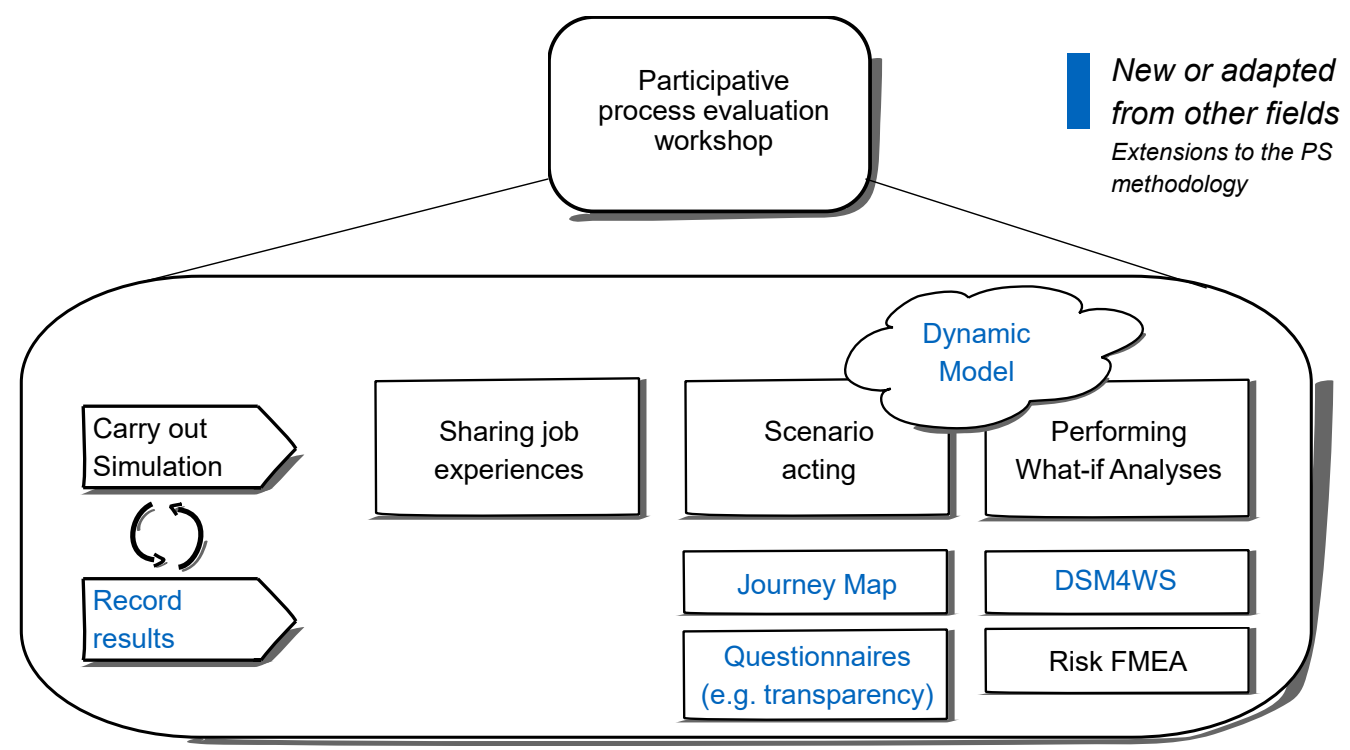

Figure 5. Activities and templates within the participative process evaluation workshop 
As illustrated on the example in Figure 6, the participants act the scenario and record their comments and experiences in a process journey map. The journey map is a predetermined template for documenting the simulation results and is addressed below in detail. Moreover, when participants engage in "what-if-discussions", the Process System can be manipulated with help of the simulation model (i.e. design object). For this purpose, we suggest having access to an experienced modeler who can assist during the simulation. Moreover after performing the scenarios, the participants record their insights, learnings and concerns in a brown paper or flipchart.

Based on the Customer Journey Map and User Journey Map, the Process Journey Map (depicted in Figure 6) was developed.

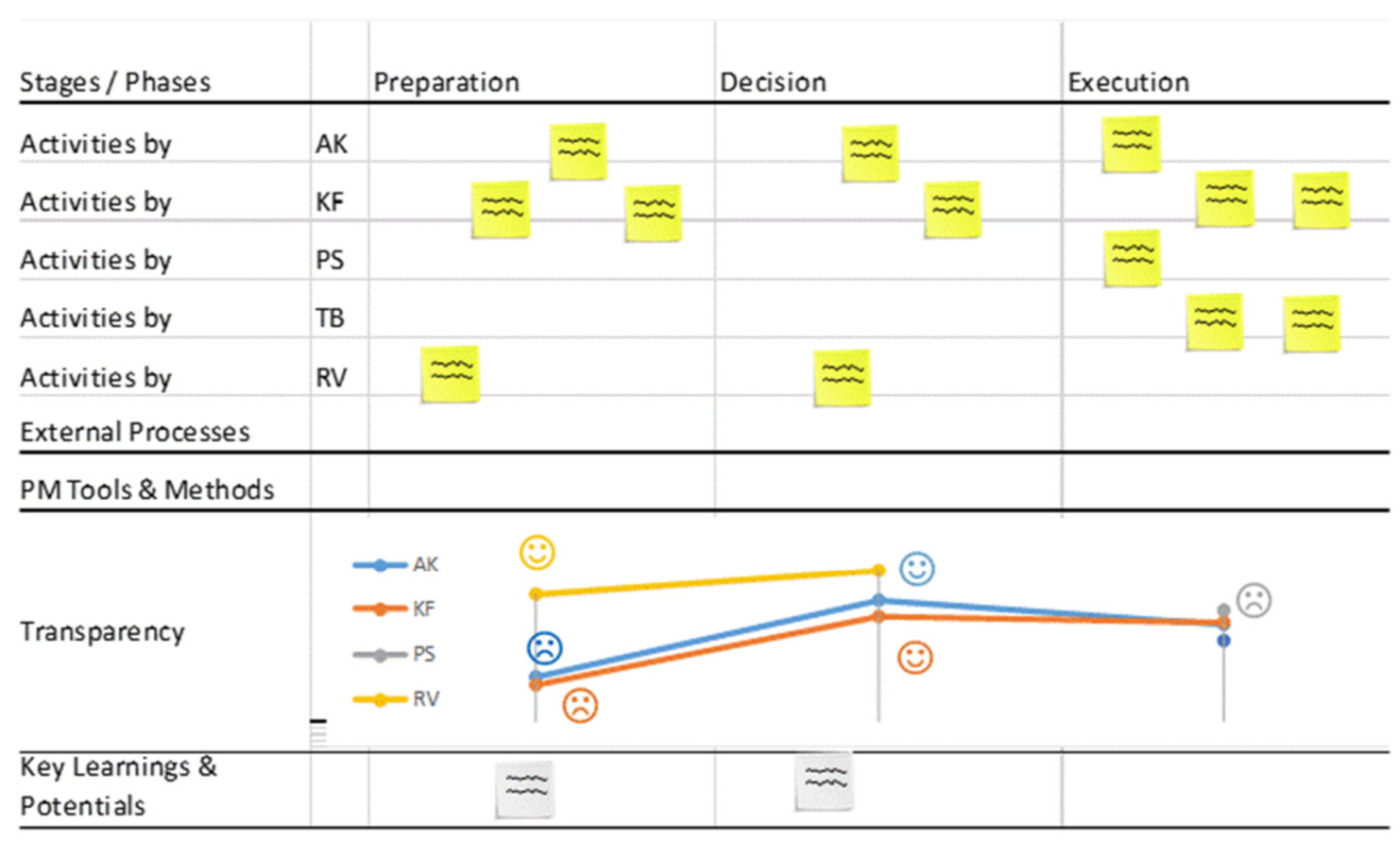

Figure 6. Process journey map with focus on transparency

In the template proposed, simulation participants should illustrate one or more of the following metrics and pieces of information within each scenario:

- Process integration (information flow) metric

- Transparency metric

- Inconsistencies (internal, external)

- Risk events

Depending upon the goals defined previously, one or more of these metrics and information pieces. In this example (Figure 6), we use the metric "transparency" and document general insights and comments from the participants as well. We define "transparency" as the characteristic of a process where, "everyone can see and understand the necessary aspects and status of an operation at all times" (Klotz et al. 2008, p. 625).

Within this approach, the transparency metric is derived from a set of predetermined questions in interviews or questionnaires after each of the scenarios. Figure 7 depicts an excerpt of a transparency questionnaire, which is however outside the scope of this paper.

Moreover, the journey map template can be adapted to further use cases and goals by adapting the metrics and questionnaires or recording further information. 


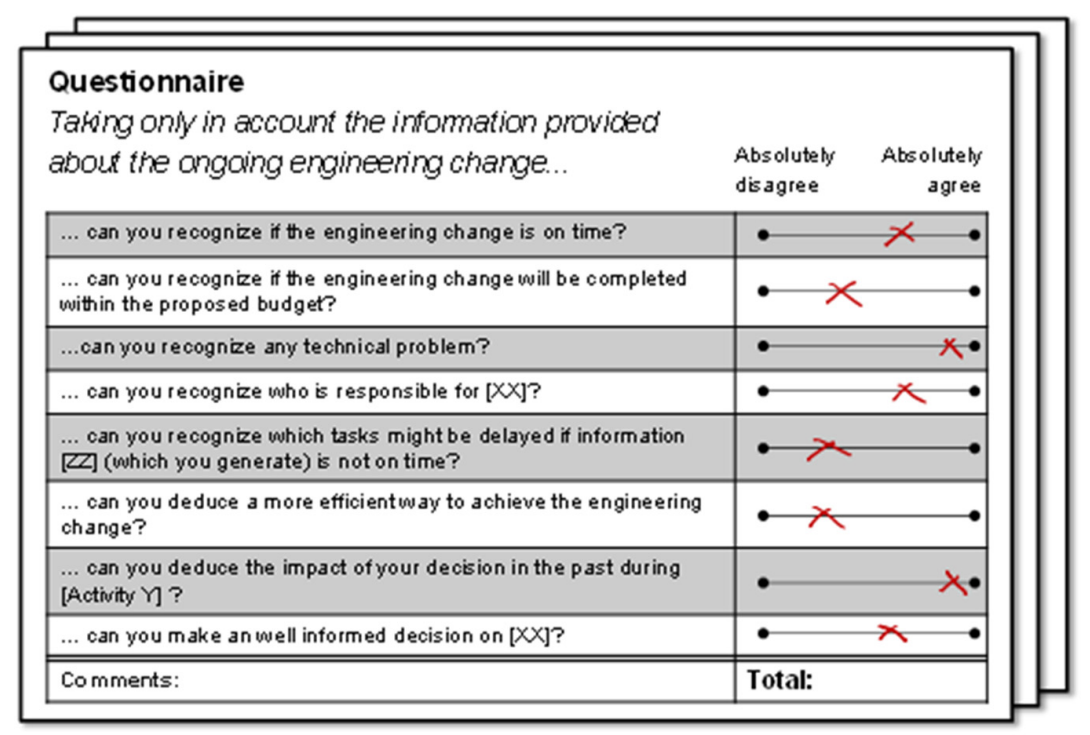

Figure 7. Transparency questionnaire (excerpt)

\subsubsection{Define actions for process improvement}

The last step summarizes and documents the results of the workshop. Hereby, the results recorded in the process journey map during the workshop are analyzed and improvement measures are developed. Positive outliers and workarounds can deliver valuable insights as well. The derived measures are then prioritized. Furthermore, insights and lessons learned regarding the S2P2I and its application can be documented.

\section{Discussion and outlook}

The simulation-supported participative process improvement (S2P2I) approach enables to integrate "process users" through participatory workshops for complex and abstract processes, such as engineering design processes. Similarly as in other participative simulations, the main outcomes are a better understanding and acceptance of the process-to-implement, as well as feedback and knowledge generation on how process participants interact with the process system in their daily work and in exceptional cases. This gained knowledge is then integrated into the design of the future process system. The main contribution is the use of dynamic process models as boundary and design objects, which allow to depict and manipulate abstract process models in a tangible way. The S2P2I was developed based on approaches from participatory ergonomics, risk management and user experience. In order to further evaluate the approach, the S2P2I should be applied in a range of industrial contexts. Ongoing work includes a case study within a large company where a sub-process is being altered.

Moreover, one main challenge for future work is to develop realistic models in an efficient manner, the transformation tool is a step towards this goal. However, further work is essential to ensure the application in industry. Further developments might include mining data from past processes to generate more realistic projects with less effort.

\section{References}

Andersen, S.N. and Broberg, O. (2017), “A framework of knowledge creation processes in participatory simulation of hospital work systems”, Ergonomics, Vol. $60 \quad$ No. 4, pp. 487-503. https://doi.org/10.1080/00140139.2016.1212999

Becerril, L., Hofmann, B., Reif, J., Kattner, N. and Lindemann, U. (2018), "Challenges with Implementing Processes, Methods and Tools in R\&D“, The ISPIM Innovation Forum, Boston, USA, March 25 - 28, 2018.

Broberg, O. (2015), "Design Processes and Constructive Ergonomics", Proceedings of the 33rd European Conference on Cognitive Ergonomics (ECCE 2015), Warsaw, Poland. https://doi.org/10.1145/2788412.2788415 
Broberg, O., Andersen, V. and Seim, R. (2011), "Participatory ergonomics in design processes: the role of boundary objects", Applied Ergonomics, Vol. 42 No. 3, pp. 464-472. https://doi.org/10.1016/j.apergo.2010.09.006

Browning, T.R., Fricke, E. and Negele, H. (2006), "Key concepts in modeling product development processes", Systems Engineering, Vol. 9 No. 2, pp. 104-128. https://doi.org/10.1002/sys.20047

Carbone, T.A. and Tippett, D.D. (2015), "Project Risk Management Using the Project Risk FMEA", Engineering Management Journal, Vol. 16 No. 4, pp. 28-35. https://doi.org/10.1080/10429247.2004.11415263

Chao, L.P. and Ishii, K. (2007), "Design process error proofing: failure modes and effects analysis of the design process”, Journal of Mechanical Design, Vol. 129 No. 5, pp. 491-501. https://doi.org/10.1115/1.2712216

Daniellou, F. (2007), "Simulating future work activity is not only a way of improving workstation design", Activités, Vol. 4 No. 2, pp. 84-90.

Hellenbrand, D. (2013), Transdisziplinäre Planung und Synchronisation mechatronischer Produktentwicklungsprozesse, $\mathrm{PhD}$ thesis, Technische Universität München.

Helten, A.K. (2015), Einführung von Lean Development in mittelständische Unternehmen: Beschreibung, Erklärungsansatz und Handlungsempfehlungen, Produktentwicklung, 1st ed., Verlag Dr. Hut, München.

Herfeld, U. (2007), Matrix-basierte Verknüpfung von Komponenten und Funktionen zur Integration von Konstruktion und numerischer Simulation, Phd thesis, Technische Universität München.

Herrmann, T. (2009), "Systems design with the socio-technical walkthrough", In: Whitworth, B. and de Moor, A. (Eds.), Handbook of research on socio-technical design and social networking systems, pp. 336-351. https://doi.org/10.4018/978-1-60566-264-0.ch023

Kasperek, D. (2016), Structure-based System Dynamics Analysis of Engineering Design Processes, PhD thesis, Technische Universität München.

Klotz, L., Horman, M., Bi, H.H. and Bechtel, J. (2008), “The impact of process mapping on transparency", International Journal of Productivity and Performance Management, Vol. 57 No. 8, pp. 623-636. https://doi.org/10.1108/17410400810916053

Kreimeyer, M. (2009), “A Structural Measurement System for Engineering Design Processes”, PhD thesis, Technischen Universität München.

Kremer, S., Krahl, T. and Lindemann, U. (2017), "User experience journeys", Proceedings of the 21th International Conference on Engineering Design (ICED 17), Vancouver, Canada, August 21 - 25, 2017, The Design Society, Glasgow.

Lévárdy, V. and Browning, T.R. (2009), “An adaptive process model to support product development project management", IEEE Transactions on Engineering Management, Vol.56 No.4, pp. 600-620. https://doi.org/10.1109/TEM.2009.2033144

Maier, A.M. and Störrle, H. (2011), "What are the characteristics of engineering design processes?”, Proceedings of the 18th International Conference on Engineering Design (ICED 11): Impacting Society through Engineering Design. Vol. 1, Copenhagen, Denmark, August 15-19, 2011, The Design Society, Glasgow, pp. 188-198.

Negele, H., Fricke, E. and Igenbergs, E. (1997), “ZOPH-A systemic approach to the modeling of product development systems”, INCOSE International Symposium, Vol. 7, Los Angeles, USA, August 3 - 7, 1997, pp. 266-273.

Nenonen, S., Rasila, H., Junnonen, J.-M. and Kärnä, S. (Eds.) (2008), “Customer Journey-a method to investigate user experience”, European Facility Management Conference, Manchester, UK, June 10 - 11, pp. 45-59.

Polson, P.G., Lewis, C., Rieman, J. and Wharton, C. (1992), "Cognitive walkthroughs: a method for theory-based evaluation of user interfaces”, International Journal of man-machine studies, Vol. 36 No. 5, pp. 741-773. https://doi.org/10.1016/0020-7373(92)90039-N

Rebentisch, E.S. (2017), Integrating program management and systems engineering: Methods, tools, and organizational systems for improving performance, John Wiley \& Sons Inc, Hoboken, New Jersey. https://doi.org/10.1002/9781119363941

Roto, V., Law, E., Vermeeren, A. and Hoonhout, J. (2011), User Experience White Paper-Bringing Clarity to the Concept of User Experience. [online] Available at: http://www.allaboutux.org/uxwhitepaper (accessed 10.12.2017).

Sterman, J. (2000), Business dynamics: Systems thinking and modelling for a complex world, Irwin/McGraw-Hill, Boston.

Thurgood, C., O'Donnell, M., Peppou, G., Lulham, R. and Bucolo, S. (2016), “A Tool to Bridge Design Innovation Research and Practice: The Project Experience Map", Proceedings of the 20th DMI: Academic Design Management Conference: Design Research Meets Design Practice at the Inflection Point, 2016, Design Management Institute, pp. 1486 - 1502. 
Todnem By, R. (2005), “Organisational change management. A critical review”, Journal of Change Management, Vol. 5 No. 4, pp. 369-380. https://doi.org/10.1080/14697010500359250

Ulrich, K.T. and Eppinger, S.D. (2003), Product design and development, Tata McGraw-Hill Education.

Vajna, S. (2005), “Workflow for design”, In: Clarkson, J. and Eckert, C. (Eds.), Design process improvement: A review of current practice, Springer Verlag London Limited, London, pp. 366-385. https://doi.org/10.1007/978-1-84628-061-0_16

van der Aalst, W. and van Hee, K.M. (2004), Workflow management: models, methods, and systems, MIT press.

Lucia Becerril, Research Associate

Technical University of Munich, Product Development and Lightweight Design

Boltzmannstrasse 15, 85748 Munich, Germany

Email: lucia.becerril@tum.de 